\title{
CLIMACTERIC SYMPTOMS AMONG WOMEN IN A RURAL AREA IN KERALA
}

S. Anil Bindhu.

1. Associate Professor. Department of Community Medicine, Sree Gokulam Medical College \&RF. Trivandrum.

\section{CORRESPONDING AUTHOR:}

Dr. S. Anil Bindhu,

Krishnagiri, Venpalavattom,

Anayara.P.O., Thiruvananthapuram

Kerala 695029

E-mail: dranilbindu@gmail.com

ABSTRACT: Every woman who lives beyond 50 years goes through a period of transition from reproductive to non-reproductive stages of life. Menopause is considered as a clinical marker of declining ovarian function. The common climacteric symptoms experienced by women during this period can be group into: vasomotor, somatic, psychological and sexual complaints.

The aim of the study was to compare the climacteric symptoms among rural women who attained menopause and those who did not attained menopause in the age group of 43-55 years. METHODS AND MATERIALS: A cross-sectional study design was conducted in a rural area in Kerala. Data were collected from 320 women by interviewing with the help of a structured questionnaire consisting of a socio-demographic data, and the Greene's Climacteric Scale. The Statistical Package for the Social Sciences software Version 16.0 was used for statistical analyses. Mann Whitney $U$ test was used to compare the total score of climacteric symptoms and each sub-scale symptom scores (psychological, somatic, and sexual scores) among women who attained and not attained menopause. The $X^{2}$ test was applied to compare the proportion of the different grades of symptoms between the different menopausal statuses. The level $\mathrm{P}<0.05$ was considered as the cut-off value for significance RESULTS: The total Greene's climacteric scale score (p: 0.001), the psychological subscale scores (p: 0.007), the somatic subscale scores ( $p: 0.022$ ) , the vasomotor subscale scores (p: 0.011 ) and the sexual subscale scores (p: 0.001) were significantly higher in women who attained menopause compared to those who did not. CONCLUSION: The climacteric symptoms vary significantly between women who attained menopause and women who did not attained menopause.

INTRODUCTION: All women who live beyond 50 years go through a period of transition from reproductive to non-reproductive stages of life. Menopause is considered as a clinical marker of declining ovarian function. It implies the permanent cessation of menstruation resulting from the loss of ovarian follicular activity. The vasomotor symptoms of hot flushes and night sweats are the characteristic symptoms of menopause. These symptoms are directly resulted from depletion of estrogen level as women approaches menopausal stage and some of these women begin to experiences these menopausal symptoms before attaining menopause. The quality of life of women varies significantly on the menopausal status. Symptoms experienced during menopause affect the quality of life in postmenopausal women. The common climacteric symptoms experienced by them can be grouped into: vasomotor, somatic, psychological or sexual complaints. The prevalence and severity of climacteric symptoms varies widely from individual to individual in the same population and also from population to population. 
Significant cultural differences in one or more vasomotor symptoms were observed in 8 of 9 studies. Vasomotor symptoms in Asian women living in India was significantly fewer compared to the migrated Asian population from the Indian subcontinent living in UK and Caucasian women living in UK

The relation of climacteric symptoms with menopausal status is studied in many studies from different parts of the world. In Australian women, significant differences were evident on the vasomotor and the depression scales on the basis of menopausal status. The total Greene Climacteric score for postmenopausal was found to be higher than premenopausal total score in a study conducted Ecuadorian population.

In India, very little information is available about issues related to the menopause. The lives of women in India are framed within a set of social, economic and cultural parameters, that menopausal issues are seen less as a problem and least recognized as potential subjects for research. But right now Indian society is going through a period of transition with marked impact on social, economic and cultural life of people, especially women. As a consequence to this menopause is recognized as a health problem, increasingly by women.

The situation in Kerala with respect to "Women and Menopause" is not different from that of India. Limited research data were available regarding climacteric symptoms experienced by women in Kerala.

OBJECTIVE: To compare the climacteric symptoms among women who attained menopause and those who did not attained menopause, in the age group of 43-55 years, in a rural area, in Kottayam district in Kerala.

MATERIALS \& METHODS: The cross sectional study was conducted in a rural area in Kottayam district in Kerala. A Panchayath which is rural in nature is purposively selected. Most of the people belonged to the middle and low socio-economic class in this Panchayath. Three wards were randomly selected for study from the selected Panchayath. The approval of institutional ethical committee was obtained. Study population included all married women between the age group of 43 to 55 years who are permanent residents of this Panchayath. A pilot survey done in 50 postmenopausal women in this village showed that the median age at menopause is 49 years. Hence it was decided to set up upper and lower age boundaries of sample population 6 years from the expected median age at menopause. To bring out the difference in climacteric symptoms, an equal number of postmenopausal and pre-menopausal women, in the same age group, were compared.

\section{Exclusion criteria:}

1. Women who had undergone surgical menopause

2. Women receiving hormone replacement therapy

3. Women who attained menopause more than five years back.

Sample size is calculated, using the anticipated prevalence of vasomotor symptoms which are the characteristic symptoms of menopause, among post- menopausal women as $42 \%$ and among premenopausal women as $27 \%$ as per the pilot study, allowing a $\beta$ error of $20 \%$ and an $\alpha$ error of $5 \%$. The formula given below is used to find determine sample size.

Formula: 


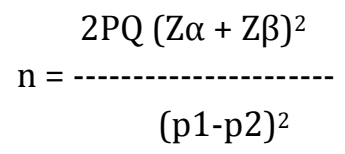

The sample size is calculated was 158.

All Post-menopausal women who met the inclusion criteria from the selected wards were included in the study. Then for every woman who had attained menopause, woman in the same age group (43-55year) who hasn't attained menopause was chosen from the same area

A pretested structured questionnaire was designed for in-depth interviews, based on information gathered from interviewing a few women prior to actual study.

Questionnaires were divided into two sections:

(1) Socio-demographic data of the women, which included: age, religion, educational level \& occupation

(2) Greene's climacteric scale

Greene's Climacteric Scale is a validated menopausal symptom scale which is used routinely in clinical practice and as a research tool. , The Greene's Climacteric Scale scores the severity of 21 symptoms on a scale of 0 to 3 and divides these symptoms into 6 sub scales. The psychological score (11 symptoms), of which Anxiety (6 symptoms), Depression (5 symptoms), The somatic score (7 symptoms), The vasomotor score $(2$ symptoms) and The sexual score (1 symptom). Total scores and each subscale scores were calculated for each woman in premenopausal and post-menopausal group. Higher scores indicate a greater number of symptoms and / or symptom severity.

All women were interviewed in the local language. Face-to-face interview conducted at the respondent's homes, ensuring adequate privacy. Respondents were informed the purpose and objectives of the research and an informed consent was obtained.

Statistical analysis:

The Statistical Package for the Social Sciences software Version 16.0 was used for statistical analyses. Mann Whitney U test was used to compare the total score of climacteric symptoms and each sub-scale symptom scores (psychological, somatic, and sexual scores) among women who attained and not attained menopause. The $\mathrm{X}^{2}$ test was applied to compare the proportion of the different grades of symptoms between the different menopausal statuses. The level $\mathrm{P}<0.05$ was considered as the cut-off value for significance

RESULTS: The cross sectional study conducted among women in the age group of 43to 55 years gave the following observations. Mean age of this sample was $48.96+/-4.04$. Majority of women $(64.4 \%)$ in the study sample were living in nuclear Family. $71.6 \%$ of the all study subjects were house wives. 57.2\% women are Hindus, $40 \%$ are Christians and 2.8\% are Muslims. Majority of women, $31.9 \%$ are educated up to high school, followed by $29.1 \%$ up to middle school. $22.8 \%$ are educated up to primary school only. $1.3 \%$ of women didn't go to school and they do not know to read or write.

The median score of total Greene's climacteric symptoms (GCS) scale among women who attained menopause was 6.5 with IQR 8and, mean score was 7.31. Among women who did not attained menopause median GCS score was 3 with IQR 9 and, mean 5.29. The minimum score obtained was 0 and maximum score was 27 in both groups. The total Greene's climacteric symptoms score was significantly higher in women who attained menopause compared to those who did not attained menopause (p: 0.001, Mann- Whitney U Test). The median score for 
psychological sub-scale among women who attained menopause was 2 with IQR 5.7and, mean score was 3.475. Among women who did not attained menopause median psychological subscale score was 1 with IQR 5 and, mean 2.79. The psychological subscale score was significantly higher in women who attained menopause compared to those who did not attained menopause (p: 0.007, Mann-Whitney U Test). The somatic subscale score was significantly higher in women who attained menopause compared to those who did not attained menopause (p: 0.022, Mann-Whitney U Test). The vasomotor subscale score was significantly higher in women who attained menopause compared to those who did not attain menopause (p: 0.011 Mann-Whitney U Test). The sexual subscale score was significantly higher in women who attained menopause compared to those who did not (p.001).

Among study subjects, only $24.4 \%$ of women reported that they have no symptoms at all. Among Pre-menopausal women in the study sample, $37.55 \%$ reported no symptoms at all, while only $11.2 \%$ of post menopausal women had no symptoms. Considering total climacteric symptoms, majority (47.8\%) were in the mildly symptomatic group. When $40 \%$ of premenopausal women reported mild symptoms, $55.6 \%$ of postmenopausal women had mild symptoms. The proportion of moderately symptomatic and severely symptomatic women was also higher among postmenopausal group compared to pre-menopausal women (table.2).

The prevalence of vasomotor symptoms (hot flashes and /night sweats) is higher among women who attained menopause $(44.8 \%)$ compared to women who did not attained menopause(33.8\%) in the same age group. This difference is found to be statistically significant with $\mathrm{p}=0.006$ and $\mathrm{OR}=1.867(1.189-2.93)$. Majority of women (31.6\%) had moderate psychological symptoms. $36.3 \%$ of postmenopausal women had moderate psychological symptoms compared to $26.9 \%$ of pre-menopausal women. $31.8 \%$ of postmenopausal women had mild psychological symptoms while $21.9 \%$ of premenopausal women experienced mild symptoms. $25.9 \%$ of women had only mild somatic symptoms. $19.4 \%$ of pre-menopausal women had mild somatic symptoms compared to $32.5 \%$ of postmenopausal with mild somatic symptoms. The proportion of women with moderate, severe and very severe somatic symptoms also, there is a slight increase in post menopausal group compared to pre-menopausal women (table.2.)

The proportion of women with complaint of sexual disinterest was significantly higher among women who attained menopause compared to women who did not attained menopause, with OR 2.854(1.814-4.492) with $\mathrm{p}$ value $<0.001$.

DISCUSSION: The total Greene Climacteric scale score and psychological, vasomotor, somatic and sexual subscale scores was found to be significantly higher among women who attained menopause compared to pre-menopausal women in this study.

In a recent study conducted among Ecuadorian population, the total Greene Climacteric scale score for postmenopausal women was found to be higher than premenopausal total score.11 In a study done by Barensten et al also it is reported that the total Greene's climacteric scale scores and psychological, vasomotor, somatic and sexual subscale scores, were higher among postmenopausal women compared to pre-menopausal women. In another study conducted in Australia, significant differences were evident on the vasomotor and the depression scales on the basis of menopausal status.10 In a large cross-sectional survey (Study of Women's Health Across the Nation) of women aged 40-55 years among racial/ethnic groups of women in the United States (Caucasian, African-American, Chinese, Japanese, and Hispanic), postmenopausal women reported significantly more vasomotor symptoms than premenopausal 
women. In a study conducted in Japan, it is reported that the vasomotor symptom prevalence rates vary according to menopause and self-assigned konnenki status.7 In the study conducted to investigate the menopausal experience of Arabic women living in Sydney, postmenopausal women suffered more vasomotor and sexual symptoms than pre- and peri-menopausal women $(\mathrm{p}<0.05)$. In a community-based study among Australian born women aged 45-55 years, there was a dramatic decline in female sexual functioning with the natural menopausal transition. Peri-menopausal women experienced the most physical and psychosocial symptoms, while postmenopausal women experienced most sexual symptoms in a study among indigenous women of Sarawak in Malaysia.

The climacteric symptoms vary significantly between women who attained menopause and women who did not. Thus menopause can lead to considerable impact on the well being of women caused by a number of somatic, psychological, vasomotor symptoms and sexual disinterest. The ignorance of the nature of menopausal symptoms may lead women, at times, to imagine that they are suffering from all sorts of illness. Hence counseling of menopausal women needs to be popularized and facilities made available to those who need them. Empowerment during the climacteric stage can contribute to improving the perception about this stage as well as the importance of self-care. 19

\section{REFERENCES:}

1. K. Peeyananjarassri, S. Cheewadhanaraks, M. Hubbard, R. Zoa Manga, R. Manocha, J. Eden. Menopausal symptoms in a hospital-based sample of women in southern Thailand. Climacteric Jan 2006; 9 (1): 23-29

2. Williams RE, Levine KB, Kalilani L, Lewis J, Clark RV. Menopause-specific questionnaire assessment in US population-based study shows negative impact on health- related quality of life. Maturitas 2009; 62(2):153-9

3. Green R, Santoro N. Menopausal symptoms and ethnicity: the Study of Women's Health across the Nation. Women's Health (Lond Engl). 2009 Mar; 5(2):127-33

4. Syed ASA Rahman, Siti R Zainudin, Verna LK Mun. Assessment of menopausal symptoms using modified Menopause Rating Scale (MRS) among middle age women in Kuching, Sarawak, Malaysia. Asia Pacific Family Medicine 2010; 9:5 doi:10.1186/1447-056X-9-5

5. Grigoriou V, Augoulea A, Armeni E, Rizos D, Alexandrou A, Dendrinos S, Panoulis K, Lambrinoudaki I Prevalence of vasomotor, psychological, psychosomatic and sexual symptoms in perimenopausal and recently postmenopausal Greek women: association with demographic, life-style and hormonal factors. Gynecol Endocrinol. 2013 Feb; 29(2):125-8. doi: 10.3109/09513590.2012.708801. Epub 2012 Jul 31

6. Liu J, Eden JA. The menopausal experience of Greek women living in Sydney. Menopause 2008 May-Jun;15(3):476-81

7. Melby MK. Vasomotor symptom prevalence and language of menopause in Japan. Menopause 2005 May-Jun; 12(3):250-7.

8. Melby MK, Anderson D, Sievert LL, Obermeyer CM. Methods used in cross-cultural comparisons of vasomotor symptoms and their determinants. Maturitas 2011 Oct; 70(2):110-9. Epub 2011 Aug 25.

9. Gupta P, Sturdee DW, Hunter MS. Mid-age health in women from the Indian subcontinent (MAHWIS): general health and the experience of menopause in women. Climacteric 2006 Feb; 9(1):13-22 
10. Travers C, O'Neill SM, King R, Battistutta D, Khoo SK. Greene Climacteric Scale: norms in an Australian population in relation to age and menopausal status. Climacteric 2005 Mar; 8(1): 56-62.

11. Sierra B, Hidalgo LA, Chedraui PA. Measuring climacteric symptoms in an Ecuadorian population with the Greene Climacteric Scale. Maturitas. 2005 Jul ; 51(3):236-45

12. Greene JG. Constructing a standard climacteric scale Maturitas 1998 May 20; 29(1):2531

13. Greene JG. Constructing a standard climacteric scale. Maturitas 2008 Sep-Oct; 61(12):78- 84

14. Barensten R. van de Weijer PH, vanGend S, Foekema H. Climacteric symptoms in a representative Dutch population sample as measured with the Greene Climacteric Scale. Maturitas 2001; 38: 123-128

15. Avis NE, Stellato R, Crawford S, Bromberger J, Ganz P, Cain V, Kagawa-Singer M. Is there a menopausal syndrome? Menopausal status and symptoms across racial/ethnic groups. Social science and medicine $2001 \mathrm{Feb}$; 52(3):345-56.

16. Lu J, Liu J, Eden J. The experience of menopausal symptoms by Arabic women in Sydney. Climacteric 2007 Feb;10(1):72-9.

17. Dennerstein L, Alexander JL, Kotz K. The menopause and sexual functioning: a review of the population-based studies. Annual review of sexual research 2003; 14:64-82.

18. Syed Alwi SA, Lee PY, Awi I, Mallik PS, Md Haizal MN. The menopausal experience among indigenous women of Sarawak, Malaysia. Climacteric 2009 Dec; 12(6):548-56.

19. S. V. Doubova, C. Infante-Castañeda, I. Martinez-Vega, R. Pérez-Cuevas. Towards healthy aging through empowering self-care during the climacteric stage. Climacteric December 2012; 15( 6) : 563-572

Table No. 1. Socio-demographic variables in the study population:

\begin{tabular}{|c|c|c|c|c|c|}
\hline \multirow{3}{*}{$\begin{array}{l}\text { Socio-demographic } \\
\text { variables } \\
\text { Age group }\end{array}$} & \multicolumn{4}{|c|}{ Menopausal status } & \multirow[t]{3}{*}{ Total } \\
\hline & \multicolumn{2}{|c|}{ Attained } & \multicolumn{2}{|c|}{ Not attained } & \\
\hline & Freq & $\%$ & Freq & $\%$ & \\
\hline$>50$ years & 97 & 82.2 & 21 & 17.8 & 118 \\
\hline 50 years or less & 63 & 31.2 & 139 & 68.8 & 202 \\
\hline \multicolumn{6}{|l|}{ Family type } \\
\hline Nuclear & 97 & $47.1 \%$ & 109 & $52.9 \%$ & 206 \\
\hline $\begin{array}{l}\text { Joint/ } \\
\text { extended }\end{array}$ & 63 & $55.3 \%$ & 51 & $44.7 \%$ & 114 \\
\hline \multicolumn{6}{|l|}{ Occupational status } \\
\hline Not employed & 111 & 48.5 & 118 & 51.5 & 229 \\
\hline Self employed & 11 & 68.7 & 5 & 31.3 & 16 \\
\hline Regular Salaried job & 19 & 61.3 & 12 & 38.7 & 31 \\
\hline Unskilled workers & 19 & 43.2 & 25 & 56.8 & 44 \\
\hline
\end{tabular}


Table No.2 Climacteric symptoms and menopausal status of women

\begin{tabular}{|c|c|c|c|}
\hline $\begin{array}{l}\text { Climacteric } \\
\text { symptoms }\end{array}$ & $\begin{array}{l}\text { Attained } \\
\text { menopause }\end{array}$ & $\begin{array}{l}\text { Not attained } \\
\text { menopause }\end{array}$ & sig \\
\hline $\begin{array}{l}\text { Total Greene's } \\
\text { Climacteric scale }\end{array}$ & & & \\
\hline $\begin{array}{l}\text { Nil } \\
\text { Mild } \\
\text { Moderate } \\
\text { Severe }\end{array}$ & $\begin{array}{cl}18 & (11.2 \%) \\
89 & (55.6 \%) \\
46 & (28.8 \%) \\
7 & (4.4 \%)\end{array}$ & $\begin{array}{ll}60 & (37.5 \%) \\
64 & (40.0 \%) \\
32 & (20.0 \%) \\
4 & (2.5 \%)\end{array}$ & $\begin{array}{l}p= \\
0.001\end{array}$ \\
\hline Psychological & & & \\
\hline $\begin{array}{c}\text { Nil } \\
\text { Mild } \\
\text { Moderate } \\
\text { Severe }\end{array}$ & $\begin{array}{lr}40 & (25.0 \%) \\
51 & (31.8 \%) \\
58 & (36.3 \%) \\
11 & (6.9 \%)\end{array}$ & $\begin{aligned} 73 & (45.6 \%) \\
35 & (21.9 \%) \\
43 & (26.9 \%) \\
9 & (5.6 \%)\end{aligned}$ & $p=0.002$ \\
\hline $\begin{array}{r}\text { Nil } \\
\text { Mild } \\
\text { Moderate } \\
\text { Severe } \\
\text { Very severe }\end{array}$ & $\begin{array}{cc}63 & (39.4 \%) \\
52 & (32.5 \%) \\
22 & (13.8 \%) \\
11 & (6.9 \%) \\
12 & (7.5 \%)\end{array}$ & $\begin{aligned} 89 & (55.6 \%) \\
31 & (19.4 \%) \\
21 & (13.1 \%) \\
9 & (5.6 \%) \\
10 & (6.3 \%)\end{aligned}$ & $p=0.038$ \\
\hline $\begin{array}{r}\text { Sexual sub scale } \\
\text { Nil } \\
\text { Mild } \\
\text { Moderate } \\
\text { Severe }\end{array}$ & $\begin{array}{l}41(32.0 \%) \\
21(16.4 \%) \\
39(30.5 \%) \\
27 \quad(21.1 \%)\end{array}$ & $\begin{array}{c}91(62.8 \%) \\
15(10.3 \%) \\
23(15.9 \%) \\
16(11 \%)\end{array}$ & $\mathrm{p}<0.001$ \\
\hline
\end{tabular}

1

Results of Chi square test

Total GCS score $0=$ nil, 1-9= mild, 10-19= moderate, $20 \&$ above $=$ severe

Psychological subscale score $0=$ nil, $1-3=$ mild, $4-9=$ moderate, 10 or more=severe

Somatic subscale score $0=$ nil, $1=$ mild, $2=$ moderate, $3=$ severe, 4 or $>4=$ very severe

Sexual subscale score $0=$ nil, $1=$ Mild, $2=$ Moderate, $3=$ Severe 
Table No. 3 vasomotor symptoms and menopausal status of women

\begin{tabular}{|c|c|c|c|c|c|}
\hline \multirow{2}{*}{$\begin{array}{c}\text { Vasomotor } \\
\text { Symptoms }\end{array}$} & \multicolumn{2}{|c|}{ Menopausal Status of Women } & & Significance & Odds ratio \\
\cline { 2 - 5 } & Attained & Not Attained & & & \\
\hline \multirow{2}{*}{ Yes } & 78 & 54 & 132 & $\mathrm{p}=0.006$ & OR=1.867 \\
& $44.8 \%$ & $33.8 \%$ & $41.2 \%$ & & (1.189-2.93) \\
& & & & \\
\hline No & $51.2 \%$ & $66.2 \%$ & $58.8 \%$ & & \\
& & & $106 \%$ & & \\
\hline Total & 160 & 160 & 320 & & \\
& $100 \%$ & $100 \%$ & $100 \%$ & & \\
& & & & & \\
& & & & & \\
\hline
\end{tabular}

